\title{
Skilled birth attendance in Sierra Leone, Niger, and Mali: analysis of demographic and health surveys
}

\author{
Edward Kwabena Ameyaw ${ }^{1 *}$ (D) and Kwamena Sekyi Dickson²
}

\begin{abstract}
Background: Skilled birth attendance (SBA) is a key strategy for averting maternal mortality ratio (MMR). The lifetime risk of maternal death is high in countries with low SBA. With the presence of a skilled birth attendant, the possibility of death owing to intrapartum-related complications or stillbirth can be reduced by $20 \%$.

Methods: Using data from the most recent Demographic and Health Surveys, we investigated the prevalence of skilled birth attendance, variations, and associated factors. The sample was drawn from women aged 15-49 who were surveyed in these countries as part of the Demographic and Health Survey (DHS) program. With multivariate logistic regression, we explored the socio-demographic factors that predict women's likelihood of seeking skilled birth attendance or otherwise.

Results: Less than half of the women in Niger, Sierra Leone, and Mali obtained skilled birth attendance, with the worst case occurring in Niger (32.6\%). Women in rural areas have less likelihood of obtaining skilled birth attendance (OR 0.21; 95\% Cl 0.16-0.28), as compared to women in urban locations. Highly educated women (OR 2.50; 95\% Cl 0.72-8.69), those who had subscribed to health insurance (OR 1.39; 95\% Cl 0.88-2.20), those who obtain four or more antenatal care visits (OR 1.63; 95\% Cl 1.43-1.86), and women who watch television at least once a week (OR 2.33; 95\% Cl 1.88-2.88) are more probable to seek SBA.

Conclusion: Interventions to increase SBA rates in these countries need to be reassessed to focus on the ruralurban disparity in healthcare, female education, and ANC attendance.
\end{abstract}

Keywords: Skilled birth attendance, Women, Mali, Niger, Sierra Leone

\section{Background}

Skilled birth attendance (SBA) is a key strategy for averting maternal mortality ratio (MMR) [1]. The lifetime risk of maternal death is high in countries with low SBA [2]. With the presence of a skilled birth attendant, the possibility of death owing to intrapartum-related complications or stillbirth can be reduced by $20 \%$ [3]. Elevating SBA rates for women can, therefore, contribute substantially toward the realization of the Sustainable Development Goal (SDG) 3. SDG three inter alia envisages the reduction of maternal mortality to 70 per 100,000 maternal mortality by 2030 [4]. To achieve this, SBA, which is

\footnotetext{
* Correspondence: edmeyaw19@gmail.com

${ }^{1}$ The Australian Centre for Public and Population Health Research, Faculty of Health, University of Technology Sydney, Sydney, NSW, Australia Full list of author information is available at the end of the article
}

delivery assisted by a skilled birth attendant, has been recognized as a protective mechanism for saving maternal and newborn lives [5-7]. A skilled birth attendant is "an accredited health professional such as a midwife, doctor, or nurse who has been educated and trained to proficiency in the skills needed to manage normal (uncomplicated) pregnancies, childbirth, and the immediate postnatal period, and in the identification, management, and referral of complications in women and newborns" [8].

Some evidence indicates that only $17 \%$ of women attain SBA in Niger, with most of them delivering at home with TBA's assistance $[9,10]$. The head of the United Nations Children's Fund (UNICEF) Niger's Maternal Health Programme stated, "Even if there were more doctors and hospitals, women would most likely not go. Due to culture, they prefer to give birth

(c) The Author(s). 2020 Open Access This article is distributed under the terms of the Creative Commons Attribution 4.0 International License (http://creativecommons.org/licenses/by/4.0/), which permits unrestricted use, distribution, and reproduction in any medium, provided you give appropriate credit to the original author(s) and the source, provide a link to the Creative Commons license, and indicate if changes were made. The Creative Commons Public Domain Dedication waiver (http://creativecommons.org/publicdomain/zero/1.0/) applies to the data made available in this article, unless otherwise stated. 
at home" [10]. This implies the absence of skilled birth attendances for most women during labour. Building more health facilities has been suggested but, as purported by the framework for evaluation of quality care in maternity services, availability of health facilities does not commensurate with utilisation [11]. It has been reported that 14,000 women die from pregnancy-related causes, with several others experiencing disabilities, infections, and varying degrees of injuries [10]. Almost $80 \%$ of Niger women marry by 18 and $40 \%$ before age 15 . Childbirth at these tender ages partly accounts for the high MMR. A woman's lifetime risk of dying as a result of childbirth or pregnancy complication is one in seven in Niger [12].

The situation in Mali does not vary from what is happening in Niger because 1 in 2 young women between 20 and 24 years give birth by 18 years, as revealed by the Demographic and Health Survey [13]. The maternal health situation in Mali is one of the poorest in subSaharan Africa in spite of the proliferation of maternal and child health driven interventions such as the USAID's Maternal and Child Survival Program (MCSP) [14]. Vast rural-urban SBA disparity exists - 51 and 92\% SBA in rural and urban settings respectively [13]. Exhibition of disrespectful and hostile behaviour by some skilled birth attendants has been documented as a possible disincentive to SBA [15]. Sierra Leone is another country in sub-Saharan Africa with similar features.

In 2016, most maternal deaths in Sierra Leone were induced by postpartum hemorrhage, a situation which could be handled by a competent skilled birth attendant under normal circumstance [16]. Pregnant women have an approximate lifetime risk of maternal mortality of 1 in 17 in Sierra Leone [17]. To improve the situation, the government introduced the Free Health Care Initiative (FHCI) in 2010 to exempt women from costs associated with maternal healthcare services [18]. However, not much has been achieved, as the country still records the highest MMR globally [17].

A thorough reflection on the foregoing, in addition to the fact that no empirical study has investigated the drivers and inhibitors of SBA on a comparable ground for these countries as far as our search indicated, warranted the need for this study. This study investigated skilled birth attendance (SBA) in Sierra Leone, Niger, and Mali. Investigating the proportion of women who obtain SBA in these countries would unearth drivers and plausible inhibiting factors associated with SBA. Consequently, we explored SBA rates and associated predictors in Sierra Leone, Niger, and Mali in order to draw the attention of governments of these countries, their partner maternal health non-governmental organizations, and other developing countries to critical factors that need to the considered to accelerate SBA.

\section{Methods}

\section{Data source}

The study made use of pooled data from current DHS conducted in Mali (2012-2013), Niger (2012), and Sierra Leone (2013). DHS is a nationwide survey collected every 5 years across low- and middle-income countries in Africa and Asia. Women aged 15-49 years who are in their reproductive age are interviewed. For the purpose of this study, only women who had information on birth history in 5 years before the survey were included. A total of 6502 women were sampled from Mali, 7432 women from Niger, and 6461 women from Sierra Leone. The Institutional Review Board of the Inner City Fund (ICF) and Ethics Committees of the Ministries of Health in Sierra Leone, Niger, and Mali approved the surveys. Permission to use the DHS data sets was granted by MEASURE DHS. The data set is accessible to the public at https://dhsprogram.com/data/available-datasets.cfm.

\section{Description of variables}

The main outcome variable was skilled birth attendance. The outcome variable was derived from the response to the question "Who assisted with the delivery?" Responses were categorized under health personnel and other person. Health personnel included doctor, nurse, nurse/midwife, and auxiliary midwife; Other people also consisted of traditional birth attendant (TBA), traditional health volunteer, community/village health volunteer, neighbours/ friends/relatives, other. For the purpose of the study, skilled birth attendance referred to births assisted by a doctor, nurse, auxiliary midwife, or nurse/ midwife.

The explanatory variables consist of residence, age, wealth status, women and partner's level of education, marital status, health insurance, number of antenatal care (ANC) visits, skilled ANC provider, getting medical help for self, money needed for treatment, distance to health facility and getting permission to go, listening to radio, and watching television. Residence was categorized as urban and rural. Age was grouped in 5 - year interval and captured as 15-19, 20-24, 25-29, 30-34, $35-39,40-44$, and 45-49. Wealth status was categorized as the poorest, poorer, middle, richer, and richest. Women and partner's levels of education were captured as no education, primary, secondary, and higher education. Marital status was captured as married, cohabitation, widowed, divorced, and separated. Health insurance was categorised as yes and no. The number of antenatal care (ANC) visits was captured as less than four visits and four or more visits. Skilled ANC provider was categorised as no 0 and yes 1 . Getting medical help for self, money needed for treatment, distance to health facility, and getting permission to go were captured as a big problem and not a big problem. Listening to radio was recorded as not 
at all, less than once a week, and at least once a week. Watching television was captured as not at all, less than once a week, and at least once a week.

\section{Data analysis}

All analyses were done using Stata version 14. Inferential and descriptive analyses were done. Descriptive analysis was reported using tables and figures. Inferential analysis was used to examine the relationship between the explanatory variables and the outcome variable. Specifically, binary logistic regression was conducted. All results of the binary logistic analyses were presented as odds ratios (ORs), with 95\% confidence intervals (CIs). The complex nature of the sampling structure of the data was adjusted using the Stata Survey command 'svyset v021 [pweight=wt], strata (v023).'

\section{Ethics approval}

The Institutional Review Board of ICF and Ethics Committees of the Ministries of Health in Sierra Leone, Niger, and Mali approved the surveys. Either written or verbal consent was provided by the women who participated in the surveys. We had permission to use the dataset from MEASURE DHS after our request was granted on 15th March 2019.

\section{Results}

\section{Descriptive results}

Among the three countries, SBA ranged between 32.6\% (in Niger) and $45.2 \%$ (in Sierra Leone), as indicated in Fig. 1. Table 1 presents SBA with key background characteristics. Women in the 45-49 age category had the least SBA in all the three countries: Sierra Leone (34.7\%), Niger (23.2\%), and Mali (24.7\%). In all these countries, high rates were reported by urban residents, with Mali urban women having $86.5 \%$.

At least 9 out of 10 women with higher educational status had SBA in Sierra Leone (94.4\%), Niger (98.0\%), and Mali (96.4\%). Falling within the richest wealth status was associated with high SBA for all the three countries: Sierra Leone (75.9\%), Niger (72.9\%), and Mali (87.4\%). More than half of the cohabiting Sierra Leonean women had SBA (54.3\%). In Niger, 7 out of 10 separated women obtained SBA (74.9\%) whereas 8 out of 10 separated women in Mali had SBA (82.8\%). For all these countries, the highest SBA occurred among women whose partners had higher education, and this was much phenomenal among those from Niger (93.7\%).

Women who had subscribed to the National Health Insurance Scheme reported high SBA particularly in Niger (80.4\%). Having four or more antenatal care (ANC) visits was consistent with relatively high SBA in Sierra Leone (48.0\%), Niger (44.7\%), and Mali (62.1\%). Women who had the service of skilled providers during ANC reported high SBA in all countries, particularly in Mali (76.5\%). Reporting that obtaining money for medical treatment was not a big problem was associated with high SBA in all the countries, especially in Sierra Leone (57.5\%).

Similarly, higher SBA was reported among women who indicated that distance to the health facility was not a major challenge in all the countries, especially Sierra Leone (57.5\%). Women who indicated that obtaining permission to seek healthcare was not a challenge reported higher SBA in Sierra Leone (45. 6\%). SBA was highly pronounced among women who listened to radio at least once a week, especially among those from Sierra Leone (54.6\%). Nearly 8 out of 10 women from Niger who watched television at least once a week had SBA (79.0\%).

\section{Multivariate logistic regression of background characteristics and SBA}

In Table 2, we present the multivariate results for background characteristics and SBA. With women aged 1519 as the reference category, those aged 25-29 had a

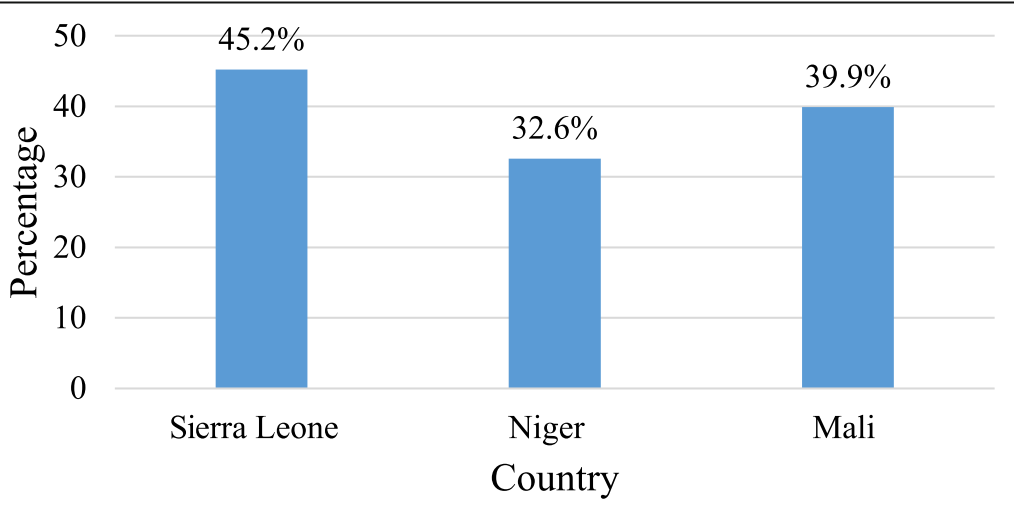

Fig. 1 Prevalence of Skilled Birth Attendance. Source: Computed from Mali DHS (2012-2013), Niger DHS (2012) and Sierra Leone DHS (2013) 
Table 1 Background characteristics and skilled birth attendance

\begin{tabular}{|c|c|c|c|c|c|c|}
\hline \multirow[t]{2}{*}{ Variables } & \multicolumn{2}{|c|}{ Sierra Leone $(n=6461)$} & \multicolumn{2}{|c|}{ Niger $(n=7432)$} & \multicolumn{2}{|c|}{ Mali $(n=6502)$} \\
\hline & Frequency & $\begin{array}{l}\text { Utilised SBAs at delivery } \\
(\%)\end{array}$ & Frequency & $\begin{array}{l}\text { Utilised SBAs at delivery } \\
\text { (\%) }\end{array}$ & Frequency & $\begin{array}{l}\text { Utilised SBAs at delivery } \\
(\%)\end{array}$ \\
\hline \multicolumn{7}{|l|}{ Age } \\
\hline $15-19$ & 417 & 45.5 & 542 & 35.4 & 534 & 37.9 \\
\hline $20-24$ & 1150 & 48.8 & 1548 & 34.8 & 1343 & 39.9 \\
\hline $25-29$ & 1677 & 48.3 & 1916 & 32.6 & 1738 & 40.9 \\
\hline $30-34$ & 1350 & 45.0 & 1558 & 30.9 & 1369 & 42.0 \\
\hline $35-39$ & 1118 & 42.5 & 1064 & 32.3 & 925 & 38.7 \\
\hline $40-44$ & 472 & 38.4 & 573 & 33.3 & 441 & 39.0 \\
\hline $45-49$ & 277 & 34.7 & 231 & 23.2 & 152 & 24.7 \\
\hline \multicolumn{7}{|l|}{ Place of residence } \\
\hline Rural & 1544 & 37.7 & 1042 & 24.2 & 1283 & 28.4 \\
\hline Urban & 4917 & 69.1 & 6390 & 84.6 & 5219 & 86.5 \\
\hline \multicolumn{7}{|l|}{ Level of education } \\
\hline No education & 4638 & 40.2 & 6303 & 27.1 & 5404 & 34.6 \\
\hline Primary & 938 & 49.3 & 760 & 56.3 & 585 & 52.5 \\
\hline Secondary & 822 & 65.2 & 343 & 76.8 & 470 & 79.1 \\
\hline Higher & 63 & 94.4 & 26 & 98.0 & 43 & 96.4 \\
\hline \multicolumn{7}{|l|}{ Wealth status } \\
\hline Poorest & 1534 & 32.9 & 1465 & 13.5 & 1339 & 16.4 \\
\hline Poorer & 1394 & 36.1 & 1477 & 21.3 & 1360 & 21.7 \\
\hline Middle & 1397 & 39.1 & 1537 & 25.0 & 1326 & 24.7 \\
\hline Richer & 1226 & 54.6 & 1566 & 33.0 & 1321 & 55.9 \\
\hline Richest & 910 & 75.9 & 1387 & 72.9 & 1156 & 87.4 \\
\hline \multicolumn{7}{|l|}{ Marital status } \\
\hline Married & 5862 & 44.6 & 7256 & 32.2 & 6360 & 39.6 \\
\hline Cohabitation & 268 & 54.3 & 10 & 51.9 & 71 & 55.7 \\
\hline Widowed & 111 & 48.6 & 43 & 32.7 & 28 & 17.7 \\
\hline Divorced & 40 & 36.7 & 113 & 53.3 & 21 & 60.5 \\
\hline Separated & 180 & 50.7 & 10 & 74.9 & 22 & 82.8 \\
\hline \multicolumn{7}{|c|}{ Partner's educational level } \\
\hline No education & 4272 & 37.4 & 6072 & 26.5 & 5356 & 34.2 \\
\hline Primary & 552 & 48.7 & 813 & 49.9 & 474 & 48.3 \\
\hline Secondary & 1318 & 62.8 & 421 & 69.1 & 550 & 77.2 \\
\hline Higher & 319 & 71.3 & 126 & 93.7 & 122 & 86.6 \\
\hline \multicolumn{7}{|l|}{ Health Insurance } \\
\hline No & 6421 & 45.0 & 7316 & 31.9 & 6356 & 39.7 \\
\hline Yes & 40 & 73.6 & 116 & 80.4 & 146 & 47.3 \\
\hline \multicolumn{7}{|c|}{ Number of ANC visits } \\
\hline Less than four & 810 & 25.9 & 5000 & 26.8 & 3803 & 24.1 \\
\hline Four or more & 5651 & 48.0 & 2432 & 44.7 & 2699 & 62.1 \\
\hline \multicolumn{7}{|c|}{ Skilled ANC provider } \\
\hline No & 2056 & 4.7 & 1285 & 4.4 & 3436 & 7.2 \\
\hline Yes & 4405 & 64.1 & 6147 & 38.5 & 3066 & 76.5 \\
\hline
\end{tabular}


Table 1 Background characteristics and skilled birth attendance (Continued)

\begin{tabular}{|c|c|c|c|c|c|c|}
\hline \multirow[t]{2}{*}{ Variables } & \multicolumn{2}{|c|}{ Sierra Leone $(n=6461)$} & \multicolumn{2}{|c|}{ Niger $(n=7432)$} & \multicolumn{2}{|c|}{ Mali $(n=6502)$} \\
\hline & Frequency & $\begin{array}{l}\text { Utilised SBAs at delivery } \\
(\%)\end{array}$ & Frequency & $\begin{array}{l}\text { Utilised SBAs at delivery } \\
(\%)\end{array}$ & Frequency & $\begin{array}{l}\text { Utilised SBAs at delivery } \\
(\%)\end{array}$ \\
\hline \multicolumn{7}{|c|}{ Getting medical help for self: money needed for treatment } \\
\hline Big problem & 4566 & 40.3 & 4561 & 28.4 & 3445 & 33.7 \\
\hline Not a big problem & 1895 & 57.0 & 2871 & 39.3 & 3057 & 46.8 \\
\hline \multicolumn{7}{|c|}{ Getting medical help for self: distance to health facility } \\
\hline Big problem & 2937 & 30.5 & 3278 & 24.4 & 2359 & 28.8 \\
\hline Not a big problem & 3524 & 57.5 & 4154 & 39.1 & 4143 & 46.2 \\
\hline \multicolumn{7}{|c|}{ Getting medical help for self: getting permission to go } \\
\hline Big problem & 1117 & 43.5 & 1534 & 33.4 & 1911 & 36.4 \\
\hline Not a big problem & 5344 & 45.6 & 5898 & 32.4 & 4591 & 41.3 \\
\hline \multicolumn{7}{|l|}{ Listening to radio } \\
\hline Not at all & 2735 & 33.3 & 2679 & 24.9 & 1969 & 28.8 \\
\hline $\begin{array}{l}\text { Less than once a } \\
\text { week }\end{array}$ & 1398 & 52.7 & 2182 & 32.2 & 1535 & 36.6 \\
\hline At least once a week & 2328 & 54.6 & 2571 & 41.1 & 2998 & 48.8 \\
\hline \multicolumn{7}{|l|}{ Watching television } \\
\hline Not at all & 5690 & 41.5 & 5795 & 25.0 & 3399 & 26 \\
\hline $\begin{array}{l}\text { Less than once a } \\
\text { week }\end{array}$ & 290 & 64.6 & 826 & 40.6 & 1242 & 41.7 \\
\hline At least once a week & 481 & 77.1 & 811 & 79.0 & 1861 & 63.7 \\
\hline
\end{tabular}

Source Computed from Mali DHS (2012-2013), Niger DHS (2012) and Sierra Leone DHS (2013)

higher likelihood of SBA in Sierra Leone (OR 1.24; 95\% CI 0.87-1.77) but all women in Niger had less SBA odds, especially those aged $45-49$ (OR 0.61 ; 95\% CI $0.36-$ 1.03). In Mali, falling within the 40-44 age category was associated with relatively higher chances of SBA (OR 1.46; 95\% CI 0.95-2.26). When checked among the three countries, women aged 45-49 had fewer odds of SBA (OR 0.66; 95\% CI 0.45-0.98). Rural women had less likelihood of having SBA for all the three countries (OR 0.21 ; 95\% CI 0.16-0.28), with the extreme occurring in Niger (OR 0.19; 95\% CI 0.14-0.28).

In Sierra Leone, those with higher education were 5 times more probable to obtain SBA (OR 5.41; 95\% CI 1.53-19.56). Women who had subscribed to health insurance had higher odds of attaining SBA (OR 1.39; 95\% CI 0.88-2.20). As compared to poorest women, richest women were noted to have higher SBA odds in all the countries (OR 2.49; 95\% CI 1.83-3.40), especially in Mali (OR 6.21; 95\% CI 3.64-10.60). In Mali, the widowed were less likely to have SBA (OR 0.28; 95\% CI 0.09-0.94). In Niger, women whose partners had attained higher education were more probable to obtain SBA (OR 3.48; 95\% CI 1.53-7.92), as compared to their counterparts whose partners do not have formal education. On the whole, women whose partners had secondary education had a high tendency of SBA (OR 1.78; 95\% CI 1.40-2.26).

\section{Discussion}

Although the efficacy of SBA in saving maternal and newborn lives is widely acknowledged [1, 19, 20], the proportion of women attaining SBA in Sierra Leone, Niger, and Mali is low, compared to other sub-Saharan African countries [21-23]. This necessitated the study to reveal the proportion of women seeking SBA and associated predictors to unearth critical factors for policydriven SBA interventions and advocacy. Place of residence, wealth status, number of ANC visits, skilled ANC provider, and watching television were significantly related to SBA.

Niger women had the least SBA whilst the highest was recorded in Mali. Less than half of the women in the reproductive age for each of these countries had SBA in the 5 years preceding the survey. Niger is a member of several international and regional treaties such as the 1978 Alma Ata Declaration of 1978, which seeks to prioritise primary health care (PHC). In May 2002, the government also adopted the Health Policy Statement, after which the Council of Ministers enacted the Health Development Plan (HDP) 2005-2009 in pursuit of maternal and child health improvement [24]. If these initiatives have not resulted in high SBA, there is the need for a critical review or other policies and interventions that would rather improve SBA. Our finding does not vary 
Table 2 Multivariate logistic regression of background characteristics and skilled birth attendance

\begin{tabular}{|c|c|c|c|c|}
\hline \multirow[t]{2}{*}{ Explanatory Variables } & Sierra Leone & Niger & Mali & All Countries \\
\hline & Odds Ratio (95\% Cl) & Odds Ratio $(95 \% \mathrm{Cl})$ & Odds Ratio (95\% Cl) & Odds Ratio $(95 \% \mathrm{Cl})$ \\
\hline \multicolumn{5}{|l|}{ Age } \\
\hline $15-19$ & Ref & Ref & Ref & Ref \\
\hline $20-24$ & $1.23(0.86-1.77)$ & $0.75(0.55-1.02)$ & $1.10(0.76-1.59)$ & $0.87(0.69-1.09)$ \\
\hline $25-29$ & $1.24(0.87-1.77)$ & $0.68^{* *}(0.50-0.92)$ & $1.26(0.90-1.76)$ & $0.89(0.72-1.11)$ \\
\hline $30-34$ & $1.03(0.70-1.53)$ & $0.67^{* *}(0.50-0.88)$ & $1.18(0.84-1.68)$ & 0.88(0.71-1.09) \\
\hline $35-39$ & $1.03(0.70-1.50)$ & $0.68^{* *}(0.51-0.93)$ & $1.19(0.79-1.76)$ & $0.86(0.68-1.09)$ \\
\hline $40-44$ & $0.87(0.58-1.33)$ & $0.80(0.56-1.14)$ & $1.46(0.95-2.26)$ & $0.99(0.76-1.30)$ \\
\hline $45-49$ & $0.81(0.52-1.29)$ & $0.61(0.36-1.03)$ & $0.86(0.45-1.63)$ & $0.66^{* *}(0.45-0.98)$ \\
\hline \multicolumn{5}{|l|}{ Place of residence } \\
\hline Urban & Ref & Ref & Ref & Ref \\
\hline Rural & $0.70(0.44-1.11)$ & $0.19^{* * *}(0.14-0.28)$ & $0.35^{* * *}(0.24-0.52)$ & $0.21^{* * *}(0.16-0.28)$ \\
\hline \multicolumn{5}{|l|}{ Level of education } \\
\hline No education & Ref & Ref & Ref & Ref \\
\hline Primary & $1.04(0.84-1.29)$ & $1.74^{* * *}(1.38-2.20)$ & $0.87(0.64-1.17)$ & $1.37^{* *}(1.14-1.63)$ \\
\hline Secondary & $1.27(0.95-1.72)$ & $1.70^{* *}(1.14-2.54)$ & $1.59(0.95-2.66)$ & $1.66^{* *}(1.24-2.22)$ \\
\hline Higher & $5.41 * *(1.53-19.56)$ & $3.05(0.38-24.60)$ & $2.33(0.48-11.24)$ & $2.50(0.72-8.69)$ \\
\hline \multicolumn{5}{|l|}{ Health Insurance } \\
\hline No & Ref & Ref & Ref & Ref \\
\hline Yes & $1.20(0.35-4.11)$ & $1.48(0.75-2.91)$ & $1.05(0.57-1.95)$ & $1.39(0.88-2.20)$ \\
\hline \multicolumn{5}{|l|}{ Wealth status } \\
\hline Poorest & Ref & Ref & Ref & Ref \\
\hline Poorer & $1.04(0.81-1.34)$ & $1.51^{* *}(1.19-1.91)$ & $1.63^{* *}(1.21-2.17)$ & $1.41^{* * *}(1.19-1.68)$ \\
\hline Middle & $1.04(0.78-1.37)$ & $1.65^{* *}(1.23-2.23)$ & $1.42^{* *}(1.03-1.95)$ & $1.41^{* *}(1.15-1.76)$ \\
\hline Richer & $1.20(0.84-1.71)$ & $2.02^{* * *}(1.52-2.67)$ & $4.03^{* * *}(2.80-5.79)$ & $2.09 * * *(1.67-2.61)$ \\
\hline Richest & $1.07(0.62-1.86)$ & $2.98^{* * *}(2.05-4.34)$ & $6.21^{* * *(3.64-10.60)}$ & $2.49^{* * *}(1.83-3.40)$ \\
\hline \multicolumn{5}{|l|}{ Marital status } \\
\hline Married & Ref & Ref & Ref & Ref \\
\hline Cohabitation & $0.83(0.60-1.15)$ & $2.14(0.48-9.55)$ & $0.82(0.33-2.02)$ & $1.43(0.62-3.29)$ \\
\hline Widowed & $1.08(0.57-2.04)$ & $1.05(0.46-2.33)$ & $0.28^{*}(0.09-0.94)$ & $0.68(0.34-1.38)$ \\
\hline Divorced & $0.50(0.23-1.09)$ & $1.61(0.87-2.97)$ & $0.99(0.29-3.36)$ & $1.22(0.69-2.15)$ \\
\hline Separated & $0.84(0.49-1.44)$ & $3.37(0.73-15.54)$ & $1.66(0.33-8.30)$ & $2.16(0.64-6.33)$ \\
\hline \multicolumn{5}{|c|}{ Partner's educational level } \\
\hline No education & Ref & Ref & Ref & Ref \\
\hline Primary & $1.21(0.90-1.63)$ & $1.54^{* * *}(1.24-1.92)$ & $0.87(0.33-2.02)$ & $1.17(0.97-1.41)$ \\
\hline Secondary & $1.59^{* * *}(1.28-1.99)$ & $2.30^{* * *(1.65-3.21)}$ & $1.14(0.79-1.66)$ & $1.78^{* * *(1.40-2.26)}$ \\
\hline Higher & $1.61 * *(1.11-2.33)$ & $3.48^{* *}(1.53-7.92)$ & $0.59(0.30-1.16)$ & $1.40(0.80-2.42)$ \\
\hline \multicolumn{5}{|l|}{ Number of ANC visits } \\
\hline Less than four & Ref & Ref & Ref & Ref \\
\hline Four or more & $2.18^{* * *}(1.68-2.83)$ & $1.40^{* * *}(1.18-1.66)$ & $1.60^{* * *}(1.30-1.96)$ & $1.63^{* * *}(1.43-1.86)$ \\
\hline \multicolumn{5}{|l|}{ Skilled ANC provider } \\
\hline No & Ref & Ref & Ref & Ref \\
\hline Yes & $29.34^{* * *}(21.90-39.31)$ & $7.92^{* * *}(5.59-11.2)$ & $26.63^{* * *}(21.25-33.38)$ & $11.51^{* * *}(9.53-13.92)$ \\
\hline
\end{tabular}


Table 2 Multivariate logistic regression of background characteristics and skilled birth attendance (Continued)

\begin{tabular}{|c|c|c|c|c|}
\hline \multirow[t]{2}{*}{ Explanatory Variables } & Sierra Leone & Niger & Mali & All Countries \\
\hline & Odds Ratio $(95 \% \mathrm{Cl})$ & Odds Ratio $(95 \% \mathrm{Cl})$ & Odds Ratio (95\% Cl) & Odds Ratio $(95 \% \mathrm{Cl})$ \\
\hline \multicolumn{5}{|c|}{ Getting medical help for self: money needed for treatment } \\
\hline Big problem & Ref & Ref & Ref & Ref \\
\hline Not a big problem & $1.11(0.90-1.39)$ & $0.95(0.80-1.12)$ & $1.04(0.83-1.31)$ & $1.08(0.94-1.24)$ \\
\hline \multicolumn{5}{|c|}{ Getting medical help for self: distance to health facility } \\
\hline Big problem & Ref & Ref & Ref & Ref \\
\hline Not a big problem & $2.07^{* * *}(1.64-2.61)$ & $1.56(0.80-1.13)$ & $1.51^{* *}(1.18-1.94)$ & $1.66^{* * *}(1.44-1.92)$ \\
\hline \multicolumn{5}{|c|}{ Getting medical help for self: getting permission to go } \\
\hline Big problem & Ref & Ref & Ref & Ref \\
\hline Not a big problem & $0.72(0.52-1.02)$ & $1.00(0.77-1.29)$ & $0.65^{* *}(0.49-0.87)$ & $0.69^{* * *}(0.56-0.84)$ \\
\hline \multicolumn{5}{|l|}{ Listening to radio } \\
\hline Not at all & Ref & Ref & Ref & Ref \\
\hline Less than once a week & $1.47^{* *}(1.14-1.88)$ & $1.07(0.87-1.32)$ & 0.94(0.69-1.29) & $0.87(0.72-1.05)$ \\
\hline At least once a week & $1.45^{* *}(1.13-1.87)$ & $1.12(0.88-1.43)$ & $1.21(0.92-1.59)$ & $1.04(0.86-2.88)$ \\
\hline \multicolumn{5}{|l|}{ Watching television } \\
\hline Not at all & Ref & Ref & Ref & Ref \\
\hline Less than once a week & $1.08(0.70-1.67)$ & $1.13(0.86-1.48)$ & $1.07(0.80-1.41)$ & $1.53^{* * *(1.26-1.86)}$ \\
\hline At least once a week & $1.58^{* *}(1.08-2.32)$ & $2.05^{* * *}(1.50-2.79)$ & $1.21(0.92-1.59)$ & $2.33^{* * *(1.88-2.88)}$ \\
\hline
\end{tabular}

from an observation suggesting that a woman's lifetime risk of dying as a result of childbirth or pregnancy complications in Niger is one in seven [12].

Women of all age cohorts had less likelihood of SBA, compared to women aged 15-19, in the case of Niger. However, in Mali and Sierra Leone, a high tendency of SBA was observed among women who had advanced in age, except those aged 45-49. The observed variation across the countries may be attributable to variation in societal acceptance of childbearing at teenage (15-19 years). Teens are likely to access the service of skilled personnel if they feel appreciated and welcomed by healthcare providers and the society in which they live [25]. Women who are advanced in age might be discouraged by the attitude of healthcare providers if they had a negative experience in the past, unlike those in the 1519 age category who might be having first deliveries and, hence, fewer chances of negative delivery experience [26]. There is consistent evidence within sub-Saharan Africa on instances where the attitude of healthcare providers dissuades women from subsequently accessing maternal healthcare services [27-29]. Some efforts have been made in Niger to enhance the uptake of SBA such as the gratuite des soins, an intervention introduced in the mid-2000s to offer free healthcare for maternity and under-fives [30].

A similar intervention has been instituted in Mali, where caesarean sections are offered free of charge in addition to some maternal services [30]. Our findings imply that these efforts need to be reconsidered, especially in the case of Niger. Burgess [31] noted that Nigerien women are faced with several challenges in utilising the existing maternal health system and, as such, are unable to obtain the required service, and this could partly result in the relatively less SBA, as observed in our study.

Rural residents had less likelihood of SBA, as compared to women in urban settings. Considering how healthcare facilities are skewed within these countries in favour of urban settings, it is expected for urban residents to have high SBA. For instance, Mali is one of the world's poorest countries, with only $2.9 \%$ of its gross domestic product (GDP) invested in healthcare, and has much healthcare concentration in its capital, Bamako [32]. Bamako alone has over 4030 (55\%) healthcare providers whereas 3279 (45\%) healthcare providers cater to the health needs of the residents outside the capital, indicating that women in remotest regions would struggle to attain SBA [33].

Similarly, in Sierra Leone, Kingham et al. [34] observed that $90 \%$ of surgeons are confined to Freetown, the capital. Data from the Human Resources for Health revealed that between 2005 and 2011, the doctor-patient ratio in Sierra Leone increased from 0.07 to 0.12 per 1000 in the western sector where the capital is located. The corresponding increase in the rural sector (Koinadugu) was from 0.03 to 0.05 per 1000 population, and the nursepatient ratio reflected the same [35]. The post-conflict fragility of the healthcare system in Sierra Leone [36] 
could partly account for the rural-urban disparity in SBA. The rural-urban disparity is not only peculiar to these countries but resonates well with literature from both developed and developing countries [37-39].

We found that the higher a woman or her partner's educational status, the higher the likelihood of SBA, as compared to women who neither have formal education nor their partners, and this was consistent for all the three countries except in Mali. Generally, educated women become more knowledgeable and conscious of their health, have more antenatal care visits, and eventually desire to obtain SBA. This outcome is consistent with some evidence from Kenya, Ethiopia, and other developing countries [40-42].

We observed that, for all the three countries, the higher a woman's wealth standing, the higher the likelihood for SBA. Having what it takes economically to gratify one's needs is a prerequisite to satiate that particular need. There might be National Health Insurance Scheme (NHIS), yet transportation costs can hinder a woman from accessing SBA. However, this cannot deter a wealthier woman from accessing skilled birth because she has the financial means and can even arrange for home delivery. The fact that wealthier women have a higher inclination toward SBA in Sierra Leone, Mali, and Niger, as observed in the present study, has consistently been reported in the literature from a number of lowand middle-income countries [39, 43-45].

In this present study, separated and divorced women had a high likelihood of SBA, as compared to married women. Could this imply their relative autonomy/empowerment as compared to women with partners? Inconsistent findings have been reported. In Ghana, Ameyaw et al. [46] indicated that married women had higher SBA inclination, compared to women who were not in any marital union. Afulani and Moyer [40], however, noted a higher likelihood of SBA among women who had never married and those who had previously married, as compared to women who were currently married.

Women who had four or more ANC visits and having skilled ANC providers were associated with a high likelihood of SBA. Similar to our findings, a Zambia-based study has also illustrated the positive association between ANC and SBA [47]. ANC is expected to be a precursor to delivery for all women globally and due to its proven gains in safeguarding maternal and newborn health, the latest WHO recommendations require women from developing world such as Mali, Sierra, and Niger to have a minimum of eight (8) ANC visits [48].

Women who reported that distance to health facilities was not a major challenge had a higher likelihood of SBA. Similarly, those who were either listening to radio or watching television at least once a week had a higher likelihood of SBA. This finding can be linked to the reproductive health initiatives that utilised the media. For instance, through the Strengthening Reproductive Health Project (SRHP), television and radio emissions were used to influence the reproductive health behaviour of about 14 million people in Mali [49]. Gaining the right information from the media (radio/television) and having no difficulty in accessing a lifesaving service are enablers for utilising that particular service. These findings coincide with some prior studies that also inquired maternal health utilisation $[39,44,50]$.

\section{Strength and limitations}

The use of large national-level comparable surveys (DHS) enhances the generalisability of our findings to other developing countries, which is a major strength of this study. However, the results need to be interpreted cautiously, as a cross-sectional study design does not permit causal-effect attribution of the observation made.

\section{Conclusion}

The study has revealed that less than half of women in Mali, Sierra Leone, and Niger utilise SBA. Having ANC with a skilled provider, being rich, and living in an urban location are essential conditions for SBA. Efforts to increase the current SBA rates in these countries ought to focus on the rural-urban disparity in healthcare, female education, and ANC attendance among these countries. The need to review existing policies, interventions, and programs aimed at improving maternal health conditions is critical, especially in Niger. Other pro-poor interventions might be needful considering the multidimensional nature of poverty. Incentives to yield equitable distribution of healthcare providers, especially among midwives and physicians, could as well be of relevance in attempts to make SBA handier for all women irrespective of location. These recommendations could apply to other subSaharan African countries struggling to elevate their current SBA rates.

\footnotetext{
Abbreviations

ANC: Antenatal Care; AOR: Adjusted Odds Ratio; Cl: Confidence Interval; DHS: Demographic and Health Survey; FHCl: Free Health Care Initiative; GDP: Gross Domestic Product; HDP: Health Development Plan; ICF: Inner City Fund; MCSP: Maternal and Child Survival Program; MMR: Maternal Mortality Ratio; NHIS: National Health Insurance Scheme; OR: Odds Ratio; PHC: Primary Health Care; SBA: Skilled Birth Attendant; SDG: Sustainable Development Goal; TBA: Traditional Birth Attendant; UNICEF: United Nations Children's Fund; USAID: United States Agency for International Development; WHO: World Health Organisation
}

Acknowledgements

We are grateful to MeasureDHS for making the data available for this study. We also thank Mr. Ebenezer Agbaglo of the Department of English, University of Cape Coast for copyediting this document for us. 


\section{Authors' contributions}

EKA and KSA conceived the study. EKA drafted the background, discussion, and conclusion. KSA conducted the analysis and drafted the methods. Both authors read and approved this final version of the manuscript.

\section{Funding}

Not applicable.

\section{Availability of data and materials}

The datasets supporting the conclusions of this article are available in the Measure DHS repository, https://dhsprogram.com/data/available-datasets.cfm.

\section{Ethics approval and consent to participate}

Ethical approval for the surveys was granted by the Ethics Committee of ORC Macro Inc. as well as Ethics Committees of the Ministries of Health in Sierra Leone, Niger, and Mali. Either written or verbal consent was provided by the women who participated in the surveys. For those below age 16, written informed consent was obtained from their parents or guardians. The authors had permission to use the dataset from MEASURE DHS after their request was granted on 15th March, 2019.

\section{Consent for publication}

Not applicable

\section{Competing interests}

The authors declare that they have no competing interests.

\section{Author details}

'The Australian Centre for Public and Population Health Research, Faculty of Health, University of Technology Sydney, Sydney, NSW, Australia.

${ }^{2}$ Department of Population and Health, College of Humanities and Legal Studies, University of Cape Coast, Cape Coast, Ghana.

\section{Received: 3 October 2019 Accepted: 21 January 2020}

Published online: 03 February 2020

\section{References}

1. WHO. Skilled birth attendants; 2019 Available from https://www.who.int/ reproductivehealth/topics/mdgs/skilled_birth_attendant/en/, [Cited 2019 December 4]

2. Carlough M, McCall M. Skilled birth attendance: what does it mean and how can it be measured? A clinical skills assessment of maternal and child health workers in Nepal. Int J Gynecol Obstet. 2005;89(2):200-8.

3. UNICEF. Delivery Care; 2019. Available from https://data.unicef.org/topic/ maternal-health/delivery-care/ [cited 2019 Dec 4].

4. United Nations. Transforming Our World: The 2030 Agenda for Sustainable Development; 2015 Available from sustainabledevelopment.un.org, [cited 2019 August 30]

5. Bongaarts J. WHO, UNICEF, UNFPA, World Bank Group, and United Nations population division trends in maternal mortality: 1990 to 2015 Geneva: World Health Organization, 2015. Popul Dev Rev. 2016:42(4):726.

6. Guevvera Y. World health organisation: neonatal and perinatal mortality: country, regional and global estimates: WHO; 2006.

7. Yakoob MY, Ali MA, Ali MU, Imdad A, Lawn JE, Van Den Broek N, et al. (2011)The effect of providing skilled birth attendance and emergency obstetric care in preventing stillbirths. BMC Public Health. 2011;11(3):S7.

8. WHO. Making pregnancy safer: the critical role of the skilled attendant: a joint statement by WHO, ICM, and FIGO; 2004.

9. The DHS Program. Niger DHS shows some improvements in child health, but maternal health remains poor [Press release]; 2007 Available from https://dhsprogram.com/Who-We-Are/News-Room/Niger-DHS-shows-someimprovements-in-child-health-but-maternal-health-remains-poor.cfm, [cited 2019 August 24]

10. The Republic of Niger. Maternal health/HIV and AIDS; 2012. [cited 2019 Aug 20] Available from https://nigersnewestchild.weebly.com/maternalhealthhiv-and-aids.html.

11. Hulton L, Matthews Z, Stones RW. A framework for the evaluation of quality of care in maternity services; 2000 . University of Southampton. Southampton.
12. UNFPA, International Confederation of Midwives (ICM), WHO. The State of the World's Midwifery 2014; 2014 Available from https://www.unfpa.org/ sowmy. [cited 2019 September 2]

13. Cellule de Planification et de Statistique, Institut National de la Statistique, Centre d'Études et d'Information Statistiques, I. C. F. International. In: Mali Enquête Démographique et de Santé (EDSM V) 2012-2013; 2014. Available from http://dhsprogram.com/pubs/pdf/FR286/FR286.pdf, [cited 2019 September 24].

14. The Borgen Project. Maternal and Child Health in Mali; 2017 Available from https://borgenproject.org/maternal-and-child-health-in-mali/, [cited 2019 July 30]

15. Warren N, Beebe M, Chase RP, Doumbia S, Winch PJ. Negenegen: sweet talk, disrespect, and abuse among rural auxiliary midwives in Mali. Midwifery. 2015;31(11):1073-80

16. Ministry of Health and Sanitation. Maternal death surveillance \& response: 2016 Annual Report; 2016 Available from https://www.afro.who.int/sites/ default/files/2017-06/mdsrreport.pdf, [cited 2019 Sept 1]

17. WHO, UNICEF, UNFPA, World Bank, United Nations. Trends in Maternal Mortality: 1990 to 2015, Estimates by WHO, UNICEF, UNFPA, World Bank Group and the United Nations Population Division; 2015. Available from https://www.who.int/reproductivehealth/publications/monitoring/maternalmortality-2015/en/, [cited 2019 Sept 4].

18. UNFPA, Sierra Leone Country Office. Free Health Care Initiative: UNFPA Support In Sierra Leone; 2013 . Available from https://sierraleone.unfpa.org/ sites/default/files/pubpdf/UNFPA_support_Free_Health_Care_Initiative.pdf, [cited 2019 August 15]

19. Amouzou A, Ziqi M, Carvajal-Aguirre L, Quinley J. Skilled attendant at birth and newborn survival in Sub-Saharan Africa. J Glob Health. 2017;7(2).

20. WHO. Facts Sheet; 2008 Available from https://www.who.int/maternal_ child_adolescent/events/2008/mdg5/factsheet_sba.pdf, [cited 2019 August 27]

21. Countdown to 2015. Tracking progress in maternal, newborn \& child survival: the 2008 report; 2008 Available from http://www.countdown2015 mnch.org/index.php?option=com_content\&view=article\&id=68\&itemid=61, [cited 2019 September 2]

22. Ghana Statistical Service (GSS), Ghana Health Service (GHS), ICF International. Ghana Demographic and Health Survey 2014; 2015 Available from https://dhsprogram.com/pubs/pdf/fr307/fr307.pdf, [cited 2019 August 29]

23. Worley, H. Rwanda's success in improving maternal health; 2015 Available from https://www.prb.org/rwanda-maternal-health/, [cited 2019 August 15]

24. Institut National de la Statistique (INS) et Macro International Inc. Enquête Démographique et de Santé et à Indicateurs Multiples du Niger 2006 [Niger Demographic and Health Survey and Multiple Indicator Cluster Survey 2006]. Calverton: INS et Macro International Inc:; 2007.

25. Pandey PL, Seale H, Razee $\mathrm{H}$. Exploring the factors impacting on access and acceptance of sexual and reproductive health services provided by adolescent-friendly health services in Nepal. PLoS One. 2019;14(8).

26. Mannava P, Durrant K, Fisher J, Chersich M, Luchters S. Attitudes and behaviours of maternal health care providers in interactions with clients: a systematic review. Glob Health. 2015;11(1):36.

27. Adewemimo AW, Msuya SE, Olaniyan CT, Adegoke AA. Utilisation of skilled birth attendance in northern Nigeria: a cross-sectional survey. Midwifery. 2014:30(1):e7-e13. https://doi.org/10.1016/..midw.2013.09.005.

28. Devkota HR, Murray E, Kett M, Groce N. Healthcare provider's attitude towards disability and experience of women with disabilities in the use of maternal healthcare service in rural Nepal. Reprod Health. 2017;14(1):79. https://doi.org/10.1186/s12978-017-0330-5.

29. Odetola TD, Fakorede EO. Assessment of Perinatal Care Satisfaction Amongst Mothers Attending Postnatal Care in Ibadan, Nigeria. Ann Glob Health. 2018:84(1).

30. Ridde V, Olivier de Sardan JP. Contradictions and inconsistencies in public policies: An analysis of healthcare fee exemption measures in Burkina Faso, Mali, Niger. In: Abolishing User Fees for Patients in West Africa: Lessons for Public Policy; 2013. Available from https://www.academia.edu/8648615/ Contradictions_and_inconsistencies_in_public_policies._An_analysis_of_ healthcare_fee_exemption_measures_in_Burkina_Faso_Mali_and_Niger, [cited 2019 September 3].

31. Burgess $S$. Creating the next steps to care: maternal health, improvisation, and Fulani women in Niamey, Niger. Anthropol Med. 2016;23(3):344-59. 
32. Bridges from Bamako. Bamako, 1997 to 2012: What's changed?; 2012 Available from https://bridgesfrombamako.com/2012/01/12/bamako-1997to-2012-whats-changed/, [cited 2019 July 29]

33. International Insulin Foundation. Mali's Health System; 2010. http://www. access2insulin.org/malis-health-system.html [cited 2019 Aug 11].

34. Kingham TP, Kamara TB, Cherian MN, Gosselin RA, Simkins M, Meissner C, et al. Quantifying surgical capacity in Sierra Leone: a guide for improving surgical care. Arch Surg. 2009;144(2):122-7.

35. Wurie H, Samai M, Witter SJRfR. Staffing the public health sector in Sierra Leone, 2005-11: findings from routine data analysis [cited 2019 September 4] Available from https://researchonline.lshtm.ac.uk/2137768/1/czv006.pdf

36. Wurie HR, Samai M, Witter S. Retention of health workers in rural Sierra Leone: findings from life histories. Hum Resour Health. 2016;14:3-3. https:// doi.org/10.1186/s12960-016-0099-6.

37. Chauhan B, Navodaya A. Skilled birth attendance across geographical regions in India: rural-urban differentials, 1992-2006. Soc Sci Spectr. 2015; 1(2):114-26.

38. Houweling TA, Ronsmans C, Campbell OM, Kunst AE. Huge poor-rich inequalities in maternity care: an international comparative study of maternity and child care in developing countries. Bull World Health Organ. 2007:85:745-54.

39. Joseph G, da Silva ICM, Barros AJ, Victora CG. Socioeconomic inequalities in access to skilled birth attendance among urban and rural women in lowincome and middle-income countries. BMJ Glob Health. 2018;3(6):e000898,

40. Afulani PA, Moyer C. Explaining disparities in use of skilled birth attendants in developing countries: a conceptual framework. PLoS One. 2016;11(4): e0154110.

41. Alemayehu M, Mekonnen W. The prevalence of skilled birth attendant utilization and its correlates in north West Ethiopia. Biomed Res Int. 2015: 436938-8. https://doi.org/10.1155/2015/436938.

42. Nyongesa C, Xu X, Hall JJ, Macharia WM, Yego F, Hall B. Factors influencing choice of skilled birth attendance at ANC: evidence from the Kenya demographic health survey. BMC Pregnancy Childbirth. 2018;18(1):88.

43. Atuoye KN, Amoyaw JA, Kuuire VZ, Kangmennaang J, Boamah SA, Vercillo S, et al. Utilisation of skilled birth attendants over time in Nigeria and Malawi. Glob Public Health. 2017;3(6):728-43. https://doi.org/10.1080/17441692.2017. 1315441.

44. Dickson $\mathrm{KS}, \mathrm{Amu} \mathrm{H}$. Determinants of skilled birth attendance in the northern parts of Ghana. In: Advances in Public Health; 2017.

45. Wong KL, Restrepo-Méndez MC, Barros AJ, Victora CG. Socioeconomic inequalities in skilled birth attendance and child stunting in selected low and middle-income countries: wealth quintiles or deciles? PLoS One. 2017 12(5):e0174823.

46. Ameyaw EK, Tanle A, Kissah-Korsah K, Amo-Adjei J. Women's health decision-making autonomy and skilled birth attendance in Ghana. Int J Reprod Med. 2016

47. Ensor T, Quigley P, Green C, Razak BA, Kaluba D, Siziya S. Knowledgeable antenatal care as a pathway to skilled delivery: modelling the interactions between use of services and knowledge in Zambia. Health Policy Plan. 2013:29(5):580-5.

48. WHO. WHO recommendations on antenatal care for a positive pregnancy experience: World Health Organization; 2016.

49. The World Bank. Implementation Completion and Results Report Health; 2017, Nutrition and Population Global Practice Africa Region. Available from https://www.google.com/url?sa=t\&rct=j\&q=\&esrc=s\&source=web\&cd= $1 \&$ cad=rja\&uact $=8 \&$ ved $=2$ ahUKEwi7iNDvuZ7nAhUImhQKHVN_ DcMQFjAAegQ|BhAB\&url=http\%3A\%2F\%2Fdocuments.worldbank.org\%2 Fcurated\%2Fen\%2F557931513362975460\%2Fpdf\%2FImplementationCompletion-and-Results-Report-ICR-Document-12082017.pdf\&usg= AOvVawOVQzB9OIMuvtMHvZAYCFQe. [cited 2019 Sept 4].

50. Karanja S, Gichuki R, Igunza P. Muhula S, Ofware P. Lesiamon et al. factors influencing deliveries at health facilities in a rural Maasai Community in Magadi sub-county, Kenya. BMC Pregnancy Childbirth. 2018;18(1):5-5. https://doi.org/10.1186/s12884-017-1632-x.

\section{Publisher's Note}

Springer Nature remains neutral with regard to jurisdictional claims in published maps and institutional affiliations.

Ready to submit your research? Choose BMC and benefit from:

- fast, convenient online submission

- thorough peer review by experienced researchers in your field

- rapid publication on acceptance

- support for research data, including large and complex data types

- gold Open Access which fosters wider collaboration and increased citations

- maximum visibility for your research: over $100 \mathrm{M}$ website views per year

At BMC, research is always in progress.

Learn more biomedcentral.com/submissions 